\title{
Periprostetik eklem enfeksiyonları (giriş, tanımlama ve sınıflamalar)
}

\author{
Periprosthetic joint infections (introduction, definition, and classifications) \\ İrfan Öztürk, Ömer Naci Ergin
}

İstanbul Üniversitesi İstanbul Tıp Fakültesi, Ortopedi ve Travmatoloji Anabilim Dalı, İstanbul

\begin{abstract}
Günümüzde periprostetik eklem enfeksiyonları, eskiden olduğu gibi, ortopedik cerrahların canını sıkmaya devam eden ana problemlerden biridir. Total eklem protezi talebi artmakta birlikte, artroplasti zemininde oluşan eklem enfeksiyonu sayısı da hızla artmaktadır. Enfeksiyon hastalığının zamanında ve doğru teşhis edilmesindeki zorluklar, bazen problemin içinden çıkılamaz bir hal almasına yol açmaktadır.

Bugüne kadar kullanılan tanımlamalar, önleyici parametreler, teşhis yöntemleri ile tedavi protokollerinin standardizasyonu ve algoritmaların, tüm ortopedi camiasında ortak yaklaşım haline gelmesi amacıyla çeşitli girişimler yapılmıştır. Bunlardan en sonuncusu olan Uluslararası Periprostetik Eklem Enfeksiyonları Ortak Görüş Toplantısı'nda, bugüne kadar üst üste konarak toplanan bilgiler, ortak görüşte buluşma çabasıyla gözden geçirilmiştir.

Bu makalede, periprostetik eklem enfeksiyonları ile ilgili son epidemiyolojik bilgiyi, ülke ekonomisine ve hastaya getirdiği yükün boyutunu, hastalığın güncel tanımını ve bugüne kadar kullanılmakta olan sınıflamaları özetleyerek, bu hastalığa genel ve güncel bir bakış açısı kazandırmayı amaçladık.
\end{abstract}

Anahtar sözcülkler: total eklem artroplastisi; periprostetik eklem enfeksiyonu; PPE; enfeksiyon; sınıflama

\begin{abstract}
Nowadays periprosthetic joint infections are among the major problems that continue to frustrate the orthopaedic surgeons, as it was in the past. Although the demand for total joint arthroplasty is increasing, the burden of joint infection occurring in the setting of arthroplasty is also increasing steeply. The difficulties in timely and accurate diagnosis of this infectious disease often lead the problem to an inextricable situation.

Some initiatives were taken with the aim of standardizing the definitions, preventive parameters, diagnostic methods and treatment protocols that have been used up to now and making the algorithms common practice in the orthopaedic society. The knowledge that was gathered superposingly up to now was reviewed at the International Consensus Meeting on Periprosthetic Joint Infections which is the latest of these attempts.

In this paper we aimed to bring in a general and up-to-date perspective on this disease by summarizing the current epidemiologic data, the burden it imposes on the national economy and the patient, the current definition of the disease and the classifications that have been used till nowadays.
\end{abstract}

Key words: total joint arthroplasty; periprosthetic joint infection; PPE; infection; classification

\section{P} eriprostetik eklem enfeksiyonları; eklem artroplasti ameliyatlarından sonra, implant çevresinde gelişen enfeksiyonlardır. Günümüzde total eklem artroplastisi (TEA); kalça ve diz eklem artritli hastaların hayat kalitesini iyileştiren ve kaybolan işlevlerini geri kazandıran güvenli ve etkili bir işlem olup ${ }^{[1,2]}$, genel başarısı tartışmasız olsa da, periprostetik eklem enfeksiyonu (PPE) gibi ameliyat sonrası komplikasyonlar ile hala karşılaşılmaktadır. ${ }^{3]}$

\section{Epidemiyoloji}

Periprostetik eklem enfeksiyonu, total eklem artroplastisi sonrası oluşabilecek en yıkıcı komplikasyonlardan birisidir. Total kalça artroplastisi (TKA) ve total diz artroplastisi (TDA) sonrası takip eden ilk iki yıl içinde ortaya çıkma insidansı \%1-2 iken ${ }^{[4,5]}$, revizyon cerrahisi sonrası \%7'ye kadar çıkmaktadır. ${ }^{[6]}$ Amerika Birleşik Devletleri'nde, revizyon cerrahisi endikasyonla$r ı$ arasında TDA sonrası birinci en sık, TKA sonrası ise üçüncü en sık neden olup, tahmin edilen prevalansları, sırasıyla $\% 1$ ve $\% 3$ civarıdır. ${ }^{[7,8]}$ TKA sonrası protezin çıkarılması nedenleri arasında ise PPE açık ara fark ile ilk sıradadır. ${ }^{[9]}$

PPE'nin hastada yol açtığı ağrı ve fonksiyon kaybını içeren fiziksel yük ve psikososyal stres tartışılmayacak derecede büyüktür. Temel bilimler alanındaki

- İletişim adresi: Prof. Dr. İrfan Öztürk, İstanbul Üniversitesi İstanbul Tıp Fakültesi, Ortopedi ve Travmatoloji Anabilim Dalı, Çapa, Fatih, İstanbul Tel: 0212 - 4142000 e-posta: ozturkirfan@hotmail.com

- Geliș tarihi: 1 Mart $2016 \quad$ Kabul tarihi: 1 Mart 2016 
araştırmaların klinik sonuçları açısından enfeksiyon hastalığı ile kanseri karşılaştıran bir editoriyal makale; bir yandan bu ikisi arasındaki birçok paralelliğe işaret ederken, diğer yandan da derin görüşlü bir bakış açısıyla, biz ortopedistlerin, hastalarımızın TEA sonrası bu istenmeyen komplikasyonun kurbanı olmaları ile farkına vardığımız böylesi yalın bir gerçeğe de ışık tutmaktadır. ${ }^{[10,11]}$ Yakın tarihli başka bir çalışma göstermiştir ki; PPE'nin tedavisi için uygulanan iki aşamalı değiştirme artroplastisi tedavisi sürecinde, birinci ve ikinci aşama arasındaki dönemde, hastaların \%7'si hayatını kaybetmektedir. ${ }^{[12]}$ Diğer bir çalışmada ise, PPE hastalarının beş yıllık mortalite oranlarının, meme kanseri, melanom, Hodgkin lenfoma ve diğer birçok kansere göre daha yüksek olduğu gözlemlenmiştir. ${ }^{[13]}$ Ekonomik yük açısından bakıldığında ise; 2001-2009 tarihleri arasında ABD kayıtları incelenerek yapılan bir çalışma süresince, PPE vakalarının tedavisi için harcama yaklaşık olarak iki katına çıkmış ve 2020 için yapılan projeksiyonda 1,62 milyar doları geçeceği öngörülmüştür. ${ }^{[14]}$

\section{Etiyoloji}

İmplante edilmiş bir protezde, küçük bir patojen popülasyonunun cerrahi sırasında yaraya girmesi, hematojen yolla yayılımı, daha öncesinde enfekte bir eklemde sepsisin tekrarlaması veya lokal bir kaynaktan enfeksiyonun komşuluk yoluyla yayılması sonucu, patojen mikroorganizmaların protez yüzeyi veya eklem boşluğundaki proliferasyonu ile PPE oluşur. ${ }^{[15,16]}$

\section{TANIM}

Yakın zamana kadar PPE için bütünleşmiş tek bir tanım yoktu. PPE'nin tanımını standardize etmek için, 2011'de Musculoskeletal Infection Society (MSIS) tarafindan bir kriterler listesi oluşturuldu. ${ }^{[17]}$ Buna ek olarak; Ağustos 2013'te ABD'nin Pensilvanya Eyaleti'nin Philadelphia şehrinde, Uluslararası Periprostetik Eklem Enfeksiyonları Ortak Görüş Toplantısı (ICM) düzenlendi. Elli iki ülkeden 400'den fazla uzman ve 130'dan fazla dernekten temsilcinin bir araya geldiği toplantıda; MSIS'in PPE tanımı desteklenmekle birlikte, bir minör kriter (lökosit esteraz testi) eklenerek ve laboratuvar test sonuçlarının eşik değerleri belirlenerek tanımın son şekli oluşturuldu. ${ }^{[18]}$

\section{Periprostetik Eklem Enfeksiyonu Tanımı ${ }^{[18]}$}

1) Eklemle (protezle) ilişkili sinus yolu varlığında veya

2) Etkilenen (protezli) eklemden elde edilen $\geq 2$ doku veya sıvı örneğinden kültür ile izole edilen ve fenotip olarak eş olan patojen varlığında veya
3) Aşağıdaki beş minör kriterden üçünün bulunması durumunda PPE tanısı konabilir:

i) Serum Eritrosit Sedimentasyon Hızı (ESR) ve Serum C-Reaktif Protein (CRP) konsantrasyonunda artış.

ii) Sinoviyal sıvıda Beyaz Kan Hücresi (WBC) sayısında artış veya Lökosit Esteraz Strip Testi'nin ++ olması.

iii) Sinoviyal sıvı Polimorfonükleer Nötrofil (PMN) yüzdesinde (\%) artış.

iv) Protez çevresindeki dokunun pozitif histolojik analizi.

v) Tek bir pozitif kültür.

Not: "Propionibacterium acnes" gibi düşük virulanslı bazı mikroorganizmaların etken olduğu enfeksiyonlarda, bu kriterler olmaksızın PPE var olabilir.

\section{SINIFLAMALAR}

Periprostetik eklem enfeksiyonlarını kategorize etmek için sınıflamalar, uzun zamandır kullanılmaktadır. Başlangıç zamanı, semptomların ne kadar sürdüğü, enfeksiyonun modu ve tedavi şeklini de içeren birçok sınıflama vardır. ${ }^{[19]}$ Mayo Clinic'ten Coventry tarafından 1975'te önerilen sınıflama, TKA sonrası PPE'yi tanımlayan ilk ve en iyi bilinen sınıflama sistemlerinden birisi olmuştur. ${ }^{[20]}$ Coventry, PPE'yi, semptomların cerrahiden ne kadar sonra ortaya çıktığına göre evrelere ayırmıştı. Yine Mayo Clinic'ten Fitzgerald, bu sınıflamayı, semptomların başlangıç zamanına ek olarak klinik prezentasyon şeklini de temel alarak, üç evreden oluşacak şekilde modifiye etti. [21] Tsukayama ve ark. bu sınıflamaya bir dördüncü evre ekledi[21,22]:

1) Evre l/erken: semptomlar ilk 4-8 hafta aralığında başlar.

2) Evre II/gecikmiş: cerrahiden sonra 3-24 ay aralığında ortaya çıkar.

3) Evre III/geç başlangıçlı: cerrahiden iki yıl sonra ortaya çıkar.

4) Evre IV/sessiz PPE: hiçbir enfeksiyon bulgusu olmayan hastanın protez revizyonu sırasında alınan kültürün pozitif olması durumudur.

Cierney ve DiPasquale, erişkin osteomiyeliti için kullanılan Cierney-Mader sınıflamasını ${ }^{[23]}$ periprostetik total eklem enfeksiyonlarına uyarlamaya çalıştılar. ${ }^{[24]}$ Bu sistemde, PPE'ler erken ve yüzeyel osteomiyelit (Tip II) veya; geç ve dirençli osteomiyelit (başlangıçtaki osteomiyelit evreleme sisteminin Tip IV'ü) olarak kaydediliyordu. 
Bu anatomik farklılaşmanın yanı sıra, yazarlar, tedavi ve prognozu etkileyebilecek lokal ve sistemik faktörleri de sınıflamaya eklediler. Bu sistemde, hastalar A, $B$, ve $C$ tipi konak olarak kategorize edilir. A tipi konaklar sağlıklıdır ve iyileşme kapasitelerinde eksiklik yoktur. B tipi konaklar bir ya da daha fazla lokal ve/veya sistemik parametre tarafindan etkilenmiştir (Tablo 1). C tipi konakların tedavilerinin morbiditesi, hastalığın morbiditesini fazlasıyla geçmekte veya küratif tedaviye dayanma kapasitesini aşmaktadır. Bu grup hastalar, agresif cerrahi tedaviden ziyade konservatif tedavi adayıdırlar.

Virolainen ve Manninen[25], lokal semptomları, sistemik semptomları, serum CRP yüksekliğini ve radyolojik bulguları, ortaya çıkış zamanları ile kombine ederek bir sınıflama önerdi (Tablo 2). Onların sınıflamasında, akut ameliyat içi enfeksiyonlar hemen ve erken enfeksiyonlar olarak, geç kronik enfeksiyonlar ise geç kronik ve geç kronik akutize olarak ikiye ayrılmaktadır.
PPE'ler patogeneze göre de (enfeksiyonun bulaş yolu) perioperatif, hematojen ve ekzojen olarak üçe ayrilır ${ }^{[26,27]}$ :

I) Perioperatif: mikroorganizmaların yaraya ameliyat sırasında veya hemen sonrasında inokulasyonu ile.

II) Hematojen: uzak bir enfeksiyon odağından kan veya lenf yoluyla yayılım.

III) Ekzojen: penetran travma, daha önceden bulunan osteomiyelit, cilt ve yumuşak doku lezyonları gibi komşu enfeksiyon odaklarından yayılım.

Erken, gecikmiş ve sessiz PPE'lerin çoğu ekzojendir. Erken PPE'lerin çoğu S.aureus gibi virulan organizmalarla oluşur. Geç PPE'lerin akut bir klinik prezentasyonu olur ve genellikle hematojendir. Sessiz PPE'lere çoğunlukla koagülaz-negatif stafilokoklar veya Propionibacterium acnes gibi düşük virulanslı bakteriler neden olur. ${ }^{[22,28]}$ En sık kontaminasyon kaynağı

Tablo 1. Cierney-DiPasquale sınıflamasına göre B tipi konakların ek morbiditeleri ${ }^{[24]}$

\begin{tabular}{ll}
\hline B (L) Konak (lokal morbidite) & B (S) Konak (sistemik morbidite) \\
\hline Kronik Lenfödem & Malnütrisyon \\
Venöz staz & Bağışılık sistemi yetmezlikleri \\
Majör damar hastalığı & Kronik hipoksi \\
Arterit & Maligniteler \\
İleri düzeyde skar dokusu & Diabetes mellitus \\
Radyasyon fibrozisi & Sınırdaki yaşlarda olmak (<2 yaş, >70 yaş) \\
İçerde kalmış yabancı cisimler (sütür, av tüfeği saçması) & Kronik nikotin kullanımı \\
& Halen nikotin kullanıyor olması
\end{tabular}

Tablo 2. Virolainen ve Manninen'in PPE sınıflaması

\begin{tabular}{|c|c|c|c|c|c|c|}
\hline & $\begin{array}{l}\text { Hemen } \\
\text { (0-3 hafta) }\end{array}$ & $\begin{array}{l}\text { Erken } \\
\text { (3h - } 3 \text { ay) }\end{array}$ & $\begin{array}{l}\text { Gecikmiş } \\
\text { (3-24 ay) }\end{array}$ & $\begin{array}{l}\text { Akut } \\
\text { hematojen }\end{array}$ & $\begin{array}{l}\text { Geç kronik } \\
\text { (>24 ay) }\end{array}$ & $\begin{array}{l}\text { Geç kronik } \\
\text { "akutize" }\end{array}$ \\
\hline $\begin{array}{l}\text { Lokal } \\
\text { semptomlar }\end{array}$ & $\begin{array}{l}\text { Şişme } \\
\text { Püy } \\
\text { Ağrı } \\
\text { Kızarıklık } \\
\text { Isı artışı }\end{array}$ & $\begin{array}{l}\text { Şişme } \\
\text { Yavaş } \\
\text { Rehabilitasyon } \\
\text { llıklık } \\
\text { Piyojenik akıntı }\end{array}$ & $\begin{array}{l}\text { Şişme } \\
\text { Yavaş } \\
\text { Rehabilitasyon } \\
\text { llıklık } \\
\text { Ağrı }\end{array}$ & $\begin{array}{l}\text { Şişme } \\
\text { Ağrı } \\
\text { Kızarıklık } \\
\text { Isı artışı }\end{array}$ & $\begin{array}{l}\text { Hiç yok veya } \\
\text { hafif şişme ve/veya } \\
\text { llıklık } \\
\text { Ağrı }\end{array}$ & $\begin{array}{l}\text { Zaten kötü olan } \\
\text { eklem daha da } \\
\text { kötüleşir }\end{array}$ \\
\hline $\begin{array}{l}\text { Sistemik } \\
\text { semptomlar }\end{array}$ & $\begin{array}{l}\text { Ateş } \\
\text { (sepsis olası) }\end{array}$ & Yok & Yok & $\begin{array}{l}\text { Ateş } \\
\text { (sepsis olası) }\end{array}$ & Yok & Ateş olabilir \\
\hline CRP & Yüksek & $\begin{array}{l}\text { Normal veya } \\
\text { yüksek }\end{array}$ & $\begin{array}{l}\text { Normal veya hafif } \\
\text { yüksek }\end{array}$ & Yüksek & Yükselmiş olabilir & Yükselmiş olabilir \\
\hline Direkt grafi & Normal & Normal & $\begin{array}{l}\text { Radyolusen } \\
\text { çizgiler olabilir }\end{array}$ & Normal & $\begin{array}{l}\text { Radyolusen } \\
\text { çizgiler olabilir }\end{array}$ & $\begin{array}{l}\text { Radyolusen } \\
\text { çizgiler olabilir }\end{array}$ \\
\hline
\end{tabular}


hastanın deri ve yumuşak dokusudur. Bununla birlikte; bazı çalışmalar, solunum, üriner veya gastrointestinal yollardan ve diş enfeksiyonlarından mikroorganizma ulaşımını da rapor etmişlerdir. ${ }^{[29]}$ Sendi ve ark. hematojen PPE'lerin \%57,5'inde, klinik prezentasyon sırasinda, birincil bakteremi veya enfeksiyona ait bulguya rastlanmamış olduğundan, enfeksiyon kaynağını belirlemenin genellikle zor olduğunu bildirmişlerdir. [30]

Periprostetik eklem enfeksiyonlarının neden olduğu morbidite ve mortalite oranlarının çok yüksek oranlarda olduğu göz önünde bulundurulduğunda, bu hastalığın erken ve doğru tanınmasının önemli olduğu görülür. Günümüzde, PPE tanısını koyarken, Uluslararası Periprostetik Eklem Enfeksiyonları Ortak Görüş Toplantısı'nda ortaya konan kriterlerin kullanılması ve sonrasında tedaviye de yön verebilecek sınıflamalardan birisi kullanılarak, bir hareket planı oluşturulması tavsiye edilebilir.

\section{KAYNAKLAR}

1. Felson DT, Lawrence RC, Hochberg MC, McAlindon T, Dieppe PA, Minor MA, Blair SN, Berman BM, Fries JF, Weinberger $M$, Lorig KR, Jacobs JJ, Goldberg V. Osteoarthritis: new insights. Part 2: treatment approaches. Ann Intern Med 2000;133(9):726-37.

2. Jones CA, Beaupre LA, Johnston DW, Suarez-Almazor ME. Total joint arthroplasties: current concepts of patient outcomes after surgery. Clin Geriatr Med 2005;21(3):527-41.

3. Lavernia CJ, Guzman JF, Gachupin-Garcia A. Cost effectiveness and quality of life in knee arthroplasty. Clin Orthop Relat Res 1997;(345):134-9.

4. Kurtz SM, Ong KL, Lau E, Bozic KJ, Berry D, Parvizi J. Prosthetic joint infection risk after TKA in the Medicare population. Clin Orthop Relat Res 2010;468(1):52-6. Crossref

5. Ong KL, Kurtz SM, Lau E, Bozic KJ, Berry DJ, Parvizi J. Prosthetic joint infection risk after total hiparthroplasty in the Medicare population. J Arthroplasty 2009;24(6 Suppl):105-9. Crossref

6. Hanssen AD, Rand JA. Evaluation and treatment of infection at the site of a total hip or knee arthroplasty. Instr Course Lect 1999;48:111-22.

7. Clohisy JC, Calvert G, Tull F, McDonald D, Maloney WJ. Reasons for revision hip surgery: a retrospective review. Clin Orthop Relat Res 2004;(429):188-92.

8. Bozic KJ, Kurtz SM, Lau E, Ong K, Chiu V, Vail TP, Rubash HE, Berry DJ. The epidemiology of revision total knee arthroplasty in the United States. Clin Orthop Relat Res 2010;468(1):4551. Crossref

9. Bozic KJ, Kurtz SM, Lau E, Ong K, Vail TP, Berry DJ. The epidemiology of revision total hiparthroplasty in the United States. J Bone Joint Surg Am 2009;91(1):128-33. Crossref

10. Rezapoor M, Parvizi J. Prevention of Periprosthetic Joint Infection. J Arthroplasty 2015;30(6):902-7. Crossref

11. Hotchkiss R, Moldawer L. Parallels between cancer and infectious disease. N Engl J Med 2014;371(4):380-3. Crossref
12. Berend KR, Lombardi AV, Morris MJ, Bergeson AG, Adams JB, Sneller MA. Two-stage treatment of hip periprosthetic joint infection is associated with a high rate of infection control but high mortality. Clin Orthop Relat Res 2013;471(2):5108. Crossref

13. Zmistowski B, Karam J, Durinka J, Casper DS, Parvizi J. Periprosthetic joint infection increases the risk of one-year mortality. J Bone Joint Surg Am 2013;95(24):2177-84. Crossref

14. Kurtz SM, Lau E, Watson H, Schmier JK, Parvizi J. Economic burden of periprosthetic joint infection in the United States. J Arthroplasty 2012;27(8 Suppl):61-5. Crossref

15. Parvizi J, Adeli B, Zmistowski B, Restrepo C, Greenwald AS. Management of periprosthetic joint infection: the current knowledge: AAOS exhibit selection. J Bone Joint Surg Am 2012;94(14):e104. Crossref

16. Della Valle CJ, Zuckerman JD, Di Cesare PE. Periprosthetic sepsis. Clin Orthop Relat Res 2004;(420):26-31.

17. Parvizi J, Zmistowski B, Berbari EF, Bauer TW, Springer BD, Della Valle CJ, Garvin KL, Mont MA, Wongworawat MD, Zalavras CG. New definition for periprosthetic joint infection: from the Work group of the Musculoskeletal Infection Society. Clin Orthop Relat Res 2011;469(11):2992-4. Crossref

18. Proceedings of the International Consensus Meeting on Periprosthetic Joint Infection. Foreword. J Orthop Res 2014;32 Suppl 1:S2-3. Crossref

19. Scuderi GR, Tria AJ, Long WJ, Kang M. Section 21: Management of the Infected Total Hip Arthroplasty. In: Scuderi GR, editor. Techniques in Revision Hip and Knee Arthroplasty. Philadelphia: Saunders Elsevier; 2014. p.580-6.

20. Coventry MB. Treatment of infections occurring in total hip surgery. Orthop Clin North Am 1975;6(4):991-1003.

21. Fitzgerald RH Jr, Nolan DR, Ilstrup DM, Van Scoy RE, Washington JA 2nd, Coventry MB. Deep wound sepsis following total hip arthroplasty. J Bone Joint Surg Am 1977;59(7):847-55.

22. Tsukayama DT, Estrada R, Gustilo RB. Infection after total hip arthroplasty. A study of one hundred and six infections. J Bone Joint Surg Am 1996;78(4):512-23.

23. Cierny G 3rd, Mader JT, Penninck JJ. A clinical staging system for adult osteomyelitis. Clin Orthop Relat Res 2003;(414):7-24.

24. Cierny G 3rd, DiPasquale D. Periprosthetic total joint infections: staging, treatment, and outcomes. Clin Orthop Relat Res 2002;(403):23-8.

25. Virolainen $P$, Manninen $M$. Periprosthetic joint infections. Suomen Ortopedia ja Traumatologia 2009;32:142-7.

26. Shahi A, Parvizi J. Prevention of Periprosthetic Joint Infection. Arch Bone Jt Surg 2015;3(2):72-81.

27. Zimmerli W, Trampuz A, Ochsner PE. Prosthetic-joint infections. N Engl J Med 2004;351(16):1645-54.

28. Zimmerli W, Moser C. Pathogenesis and treatment concepts of orthopaedic biofilm infections. FEMS Immunol Med Microbiol 2012;65(2):158-68. Crossref

29. Maderazo EG, Judson $S$, Pasternak $H$. Late infections of total joint prostheses. A review and recommendations for prevention. Clin Orthop Relat Res 1988;(229):131-42.

30. Sendi P, Banderet F, Graber P, ZimmerliW. Clinical comparison between exogenous and haematogenous periprosthetic joint infections caused by Staphylococcus aureus. Clin Microbiol Infect 2011;17(7):1098-100. Crossref 